\title{
Research on the Relationship between Interfacial Tension of ASP Compound System and Recovery Ratio
}

\author{
Shi Lei \\ No.1 Oil Production Plant, Daqing Oilfield, Daqing, China. \\ 13836957325@163.com
}

\begin{abstract}
The ASP flooding is a highly effective tertiary oil recovery method, through the synergistic action of alkali, surfactant and polymer three substances, the ultra-low interfacial tension is formed between the displacement system and the crude oil, meanwhile the polymer makes the system has a higher viscosity, so the ASP flooding can enlarge swept volume and improve washing oil efficiency, thus increasing the ultimate recovery ratio of the oil layer to a greater extent. Since entering industrial application, as the production scale has been expanding, the demand for chemicals, especially surfactants, has increased year by year, due to technology limitations; the increase in demand has caused surfactant performance to be unstable, and the detected interfacial tension cannot meet the design requirements of scheme, which cause the oil recovery ratio of the oil layer to be affected to different degrees, therefore, it is necessary to study the relationship between the different interfacial tensions of the surfactant and the recovery ratio, and understand the relationship between the interfacial tension and the improvement extent of recovery ratio. This paper starts from the oil displacement mechanism of ASP flooding, combines the laboratory tests and numerical simulation research results, gives effect of different interfacial tension on the recovery ratio of the second type oil layer, and provides a theoretical basis for the evaluation of the development effect of the oil layer ASP flooding.
\end{abstract}

Keywords: interfacial tension, ASP flooding, recovery ratio.

\section{Introduction}

The ASP flooding has the double effects of improving the sweep efficiency and the oil displacement efficiency. It is to make full use of different functions of the alkali, surfactant and polymer three chemicals, the synergistic effects of medicaments, and achieve good oil displacement effect [1].

\section{ASP Flooding Displacement Mechanism}

\subsection{Solution effect of polymer}

The high polymer of the compound system can increase the viscosity of the aqueous solution by dozens of times or even hundreds of times, thereby greatly reducing the water-oil mobility ratio, making the displacement fluid approach the piston-type displacement, greatly reduce the displacement fluid flow fingering, and improve volume sweep efficiency [2].

\subsection{Surfactant and alkali effect}

The major objective of these two chemicals is to increase washing oil efficiency of compound flooding. The mechanism is mainly to reduce the oil-water interfacial tension; the early research results describe it as follows: whether the oil drops existing in different pore media and sizes can start moving, which are directly related to the capillary dimensionless number [3-4].

The capillary dimensionless number is the ratio of the driving force and the capillary resistance during the two-phase flow process, namely:

$$
N_{c}=\frac{\mu_{W} v}{\sigma_{\text {ow }}}
$$

The method to increase the capillary dimensionless number is: 
The first is to increase the displacement speed, but generally the speed can only increase by 2 to 3 times;

The second is to increase the viscosity of the displacement fluid, and the maximum increase of viscosity is 10 to 50 times;

The third is to reduce the oil-water interfacial tension; high-efficiency surfactants can reduce the interfacial tension by 3 to 4 orders of magnitude, namely increase the capillary dimensionless number by 3 to 4 orders of magnitude.

The mechanism of the ASP flooding is to use this theory to give full play to the good synergistic effect between the compound alkaline flooding and surfactant, make the oil-water interfacial tension reduced to $1 \times 10-3 \mathrm{mN} / \mathrm{m}$ order of magnitude and below, thereby starting residual oil in the porous media, and improve oil displacement efficiency

In addition, indoor research and field tests show that the emulsification performance of ASP compound system, the change of wettability and viscoelasticity of the rock surface are also beneficial to enhance recovery ratio, because this paper mainly studies the relationship between interfacial tension and recovery ratio, there will be no further description here.

\section{Laboratory Test Research on the Relationship between Interfacial Tension and Recovery Ratio}

The interfacial tension is the tightening force which is in the tangent direction on the liquid level, and vertically acts on the unit length line segment. The dynamic interfacial tension is the interfacial tension before reaching the equilibrium value; the equilibrium interfacial tension is the stable value of the interfacial tension after a certain period of time. Under the action of ultra-low interfacial tension, the residual oil is continuously stripped into small oil drops, which are carried away by the flowing system, at the same time, the resistance which the system enters the throat is reduced due to the decrease of the oil-water interfacial tension, and the residual oil is passively used, followed by the surfactant system, and finally produced.

Through a large number of laboratory physical model flooding tests, a quantitative relationship between different interfacial tensions and oil displacement efficiency is established. From the data: different levels of interfacial tension have a great influence on the oil displacement efficiency, and the oil displacement efficiency differs 5.6 percentage points from $10-2$ to $10-4 \mathrm{mN} / \mathrm{m}$, but when the interfacial tension is less than $10-3 \mathrm{mN} / \mathrm{m}$ order of magnitude, the increase in oil displacement efficiency has slowed down significantly [5] (Figures 1, 2).

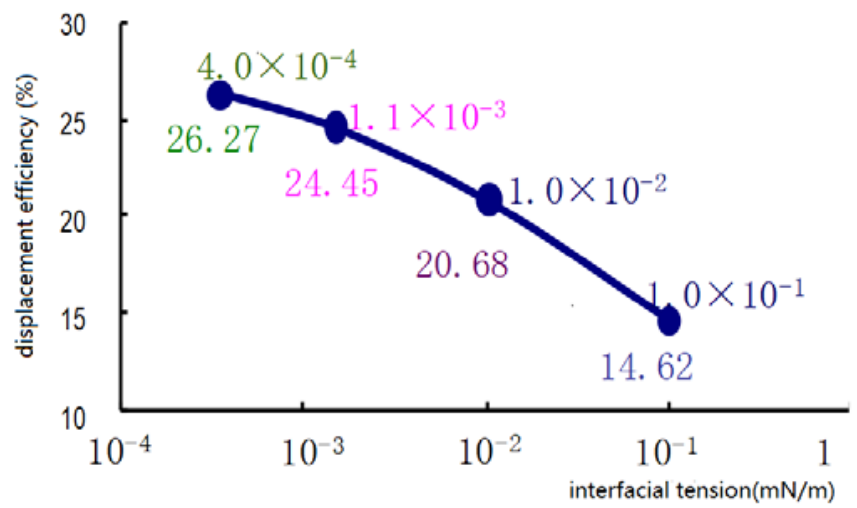

Fig.1 Relationship between equilibrium interfacial tension and oil displacement efficiency 


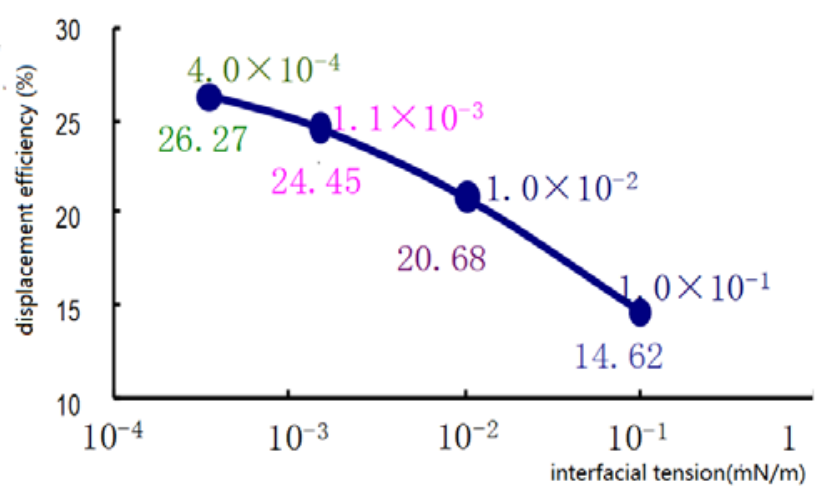

Fig.2 Relationship between dynamic interfacial tension and oil displacement efficiency

\section{Numerical Simulation Research on the Relationship between Interfacial Tension and Recovery Ratio}

In order to further make the relationship between interface tension at different levels and recovery ratio clear, numerical simulation technology is applied to study the corresponding relationship between the two. The geological model selects a certain second type of oil layer block in Sazhong Development Zone, the oil-bearing area is $8.5 \mathrm{~km} 2$, there are 510 oil and water wells, including 250 oil wells and 260 injection wells, the sandstone thickness of oil layer is $16.5 \mathrm{~m}$, the effective thickness is $11.1 \mathrm{~m}$. The effective permeability is $521 \mathrm{mD}$ [6].

Under the strong base ASP compound system, as the interfacial tension decreases, the more water content decreases, the higher the recovery ratio. When the interfacial tension activity is reduced from 100 to $10-3 \mathrm{mN} / \mathrm{m}$ order of magnitude, the recovery degree increases from $10.19 \%$ to $17.85 \%$, and increase is $7.66 \%$ (Table 1, Figure 3, 4).

Table 1 Enhanced recovery ratio under different active surfactant conditions

\begin{tabular}{|c|c|c|c|c|}
\hline $\begin{array}{c}\text { activity(order of } \\
\text { magnitude) }\end{array}$ & $\begin{array}{c}\text { containing water } \\
\text { minimum value } \\
(\%)\end{array}$ & $\begin{array}{c}\text { recovery } \\
\text { extent } \\
(\%)\end{array}$ & $\begin{array}{c}\text { enhanced recovery } \\
\text { ratio(\%) }\end{array}$ & $\begin{array}{c}\text { value added of enhanced } \\
\text { recovery ratio(\%) }\end{array}$ \\
\hline $\begin{array}{c}\text { water drive } \\
\text { prediction }\end{array}$ & - & 1.56 & - & - \\
\hline 100 & 91.01 & 10.19 & 8.63 & - \\
\hline $10^{-1}$ & 89.37 & 12.52 & 10.96 & 2.33 \\
\hline $10^{-2}$ & 87.96 & 14.91 & 13.35 & 4.72 \\
\hline $10^{-3}$ & 86.67 (ideal) & 17.85 & 16.29 & 7.66 \\
\hline
\end{tabular}

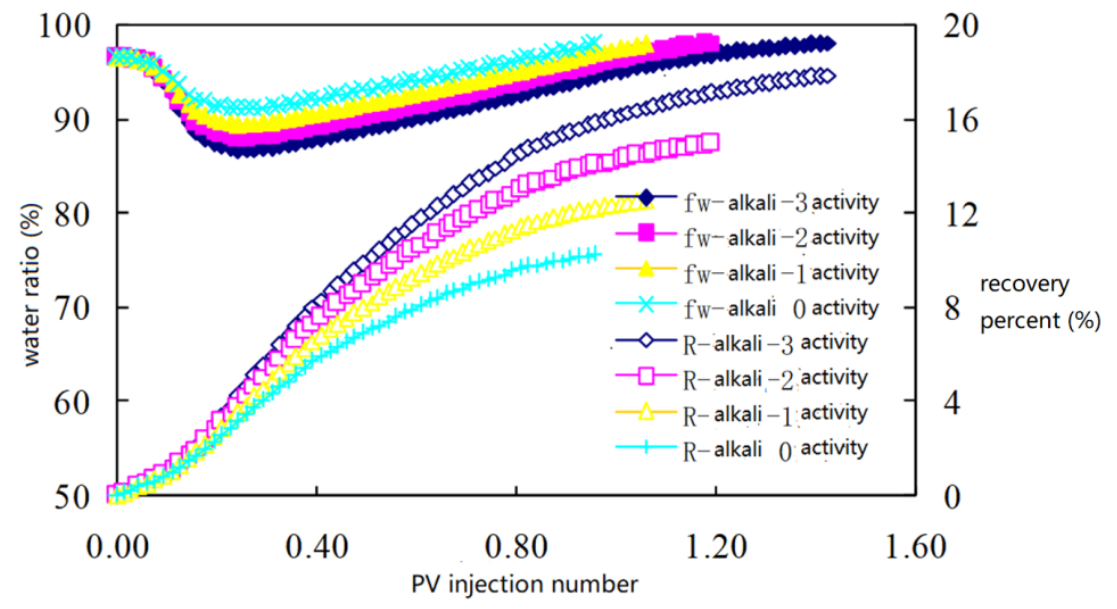

Fig.3 Relationship among water content, recovery extent and PV injection 


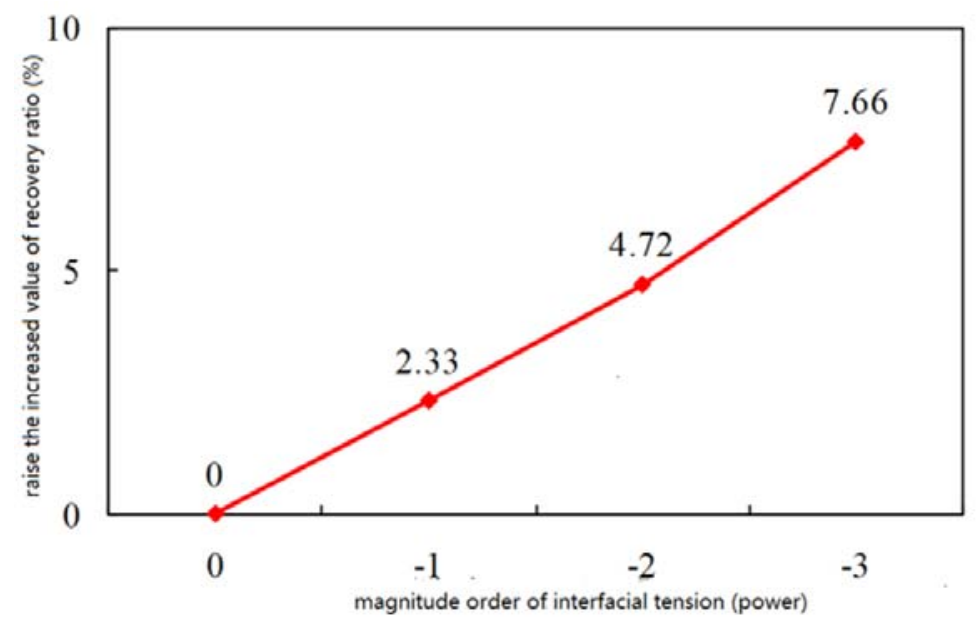

Fig.4 Relationship between increased range of recovery ratio and interfacial tension

Under the weak base ASP flooding system, as the interfacial tension decreases, the water content decreases more, the recovery ratio is higher. When the interfacial tension activity is reduced from 100 to the order of $10-3 \mathrm{mN} / \mathrm{m}$, the recovery extent increases from $11.15 \%$ to $17.99 \%$, and increase is 6.84\% (Table 2, Figures 5, 6).

Table 2 Enhanced recovery ratio under different active surfactant conditions

\begin{tabular}{|c|c|c|c|c|}
\hline $\begin{array}{c}\text { activity(order of } \\
\text { magnitude) }\end{array}$ & $\begin{array}{c}\text { containing water } \\
\text { minimum value } \\
(\%)\end{array}$ & $\begin{array}{c}\text { recovery } \\
\text { extent } \\
(\%)\end{array}$ & $\begin{array}{c}\text { enhanced recovery } \\
\text { ratio(\%) }\end{array}$ & $\begin{array}{c}\text { value added of enhanced } \\
\text { recovery ratio(\%) }\end{array}$ \\
\hline water drive prediction & - & 1.56 & - & - \\
\hline $10^{0}$ & 90.23 & 11.15 & 9.59 & 1.96 \\
\hline $10^{-1}$ & 88.97 & 13.11 & 11.55 & 4.03 \\
\hline $10^{-2}$ & 87.63 & 15.18 & 13.62 & 6.84 \\
\hline $10^{-3}$ & 86.37 & 17.99 & 16.43 & \\
\hline
\end{tabular}

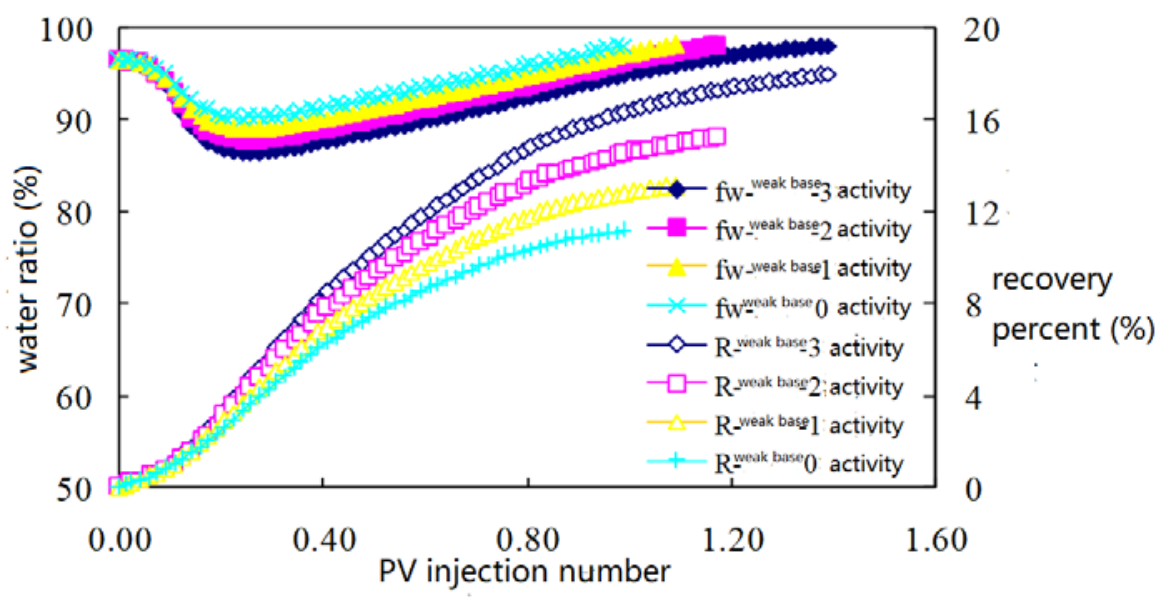

Figure 5 Relationship among water content, recovery extent, and PV injection 


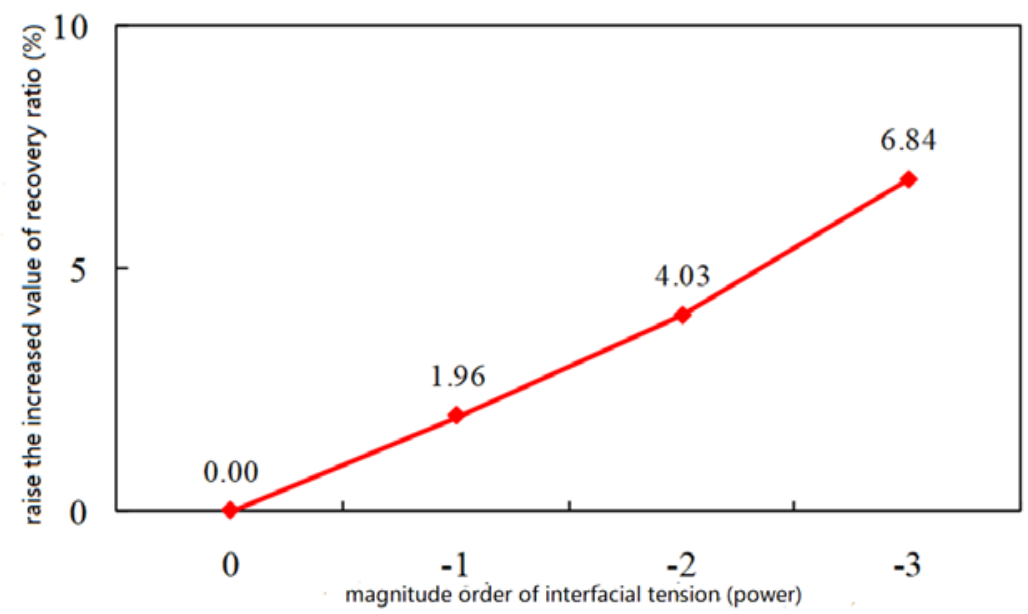

Figure 6 Relationship between increased range of recovery ratio and interfacial tension

Taking the interfacial tension with $10-3 \mathrm{mN} / \mathrm{m}$ as an example, the interfacial tension of the weak base system is lower than that of the strong base system under the same surfactant concentration and alkali concentration. In the process of oil displacement, the lower the interfacial tension, the larger the number of capillary tubes, the smaller the adhesion function, the higher the recovery ratio, Therefore, the recovery ratio of this weak base system is slightly higher than that of the strong base system (Fig. 7).

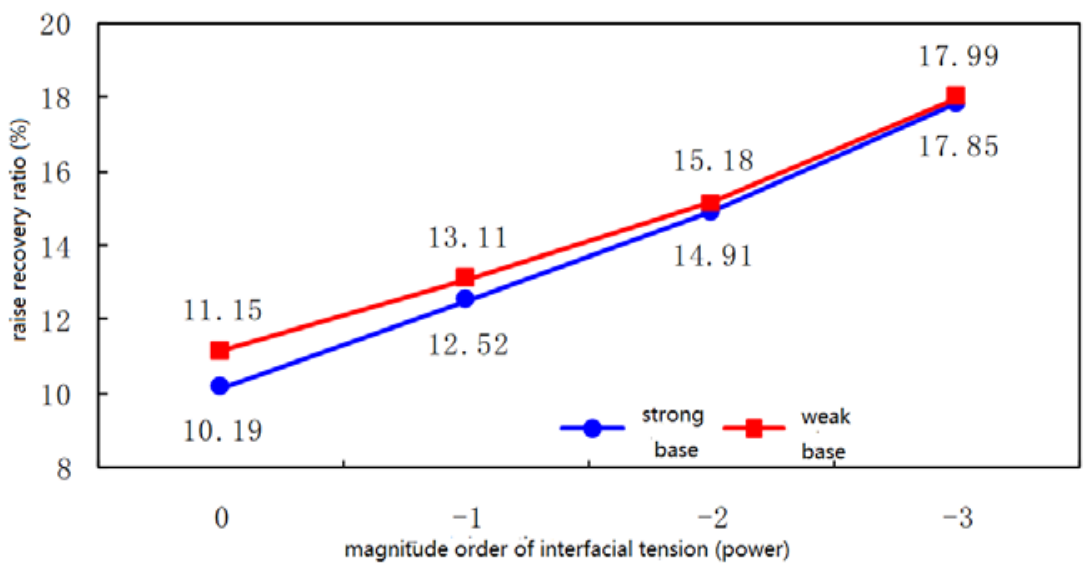

Figure 7 Comparison diagram of the increased value of the recovery ratio between strong base and weak base in different orders of magnitude activity

\section{Conclusion}

The lower the system interfacial tension, the greater the enhanced recovery ratio of the oil layer, when the interfacial tension is lower than a certain order of magnitude, the increase of recovery ratio gradually slows down;

At present, the laboratory test has a deep understanding for the displacement mechanism of ASP flooding, but there are still some cognitive defects.

First, A quantitative description for scaling law cognition of combination flooding in layer, evaluation criteria for affecting injection and production capacity; Second, compound system in the layer motion process, there is chemical chromatograph phenomenon, and it is necessary to reunderstand its motion law in the layer.

\section{References}

[1]. Guo Chunping, Zhu Huifeng. Correlation research between interfacial tension of ASP compound system and oil displacement efficiency[J], Natural Gas and Oil, 2011, 29(4) 
[2]. Yu Shenghong, Mo Shizhen. A study on features of oil displacement of alkali-surfactant-polymer flooding [J], Henan Petroleum, 2005, 19(2).

[3]. Zhu Sheyao, Zhao Zhenguo. Interface chemistry foundation. Beijing: Chemical Industry Press, 1999, 135.

[4]. Jiao Xueying, He Mingbo. New technology application of lactescence and emulsification technology - preparation and application of special emulsion chemicals, Beijing: Chemical Industry Press.

[5]. Lai Xiaojuan, Zhang Yuchao, Guo Liang, Yao Baisheng. Study on oil displacement properties of sufactant with ultra-low interfacial tension [J], Speciality Petrochemicals, 2014, 31 (4).

[6]. Yuan Qingsheng. Research on dynamic interfacial tension characteristics and influencing factors [J], Petroleum Geologyand and Recovery Efficiency, 2003, 10(3). 